\title{
Endovascular stroke treatment in orally anticoagulated patients: an analysis from the German Stroke Registry-Endovascular Treatment
}

\author{
Clemens Küpper ${ }^{1}$ (1) Katharina Feil $^{1,2,3} \cdot$ Frank Arne Wollenweber $^{4} \cdot$ Steffen Tiedt ${ }^{5} \cdot$ Moriz Herzberg $^{6}$. \\ Franziska Dorn $^{6,7} \cdot$ Thomas Liebig $^{6} \cdot$ Marianne Dieterich $^{1,2,8} \cdot$ Lars Kellert $^{1} \cdot$ for the GSR investigators $^{2}$
}

Received: 18 September 2020 / Revised: 9 December 2020 / Accepted: 10 December 2020 / Published online: 29 December 2020

(c) The Author(s) 2020

\begin{abstract}
Background Endovascular treatment (ET) in orally anticoagulated (OAC) patients has not been evaluated in randomized clinical trials and data regarding this issue are sparse.

Methods We analyzed data from the German Stroke Registry-Endovascular Treatment (GSR-ET; NCT03356392, date of registration: 22 Nov 2017). The primary outcomes were successful reperfusion defined as modified thrombolysis in cerebral infarction (mTICI 2b-3), good outcome at 3 months (modified Rankin scale [mRS] 0-2 or back to baseline), and intracranial hemorrhage (ICH) on follow-up imaging at $24 \mathrm{~h}$ analyzed by unadjusted univariate and adjusted binary logistic regression analysis. Additionally, we analyzed mortality at 3 months with adjusted binary logistic regression analysis.

Results Out of 6173 patients, there were 1306 (21.2\%) OAC patients, 479 (7.8\%) with vitamin K antagonists (VKA) and 827 (13.4\%) with non-vitamin K antagonist oral anticoagulation (NOAC). The control group consisted of 4867 (78.8\%) non-OAC patients. ET efficacy with the rates of mTICI $2 \mathrm{~b}-3$ was similar among the three groups $(85.6 \%, 85.3 \%$ vs $84.3 \%$, $p=0.93$ and 1). On day 90, good outcome was less frequent in OAC patients $(27.8 \%, 27.9 \%$ vs $39.5 \%, p<0.005$ and $<0.005)$. OAC status was not associated with ICH at $24 \mathrm{~h}$ (NOAC: odd's ratio [OR] 0.89, 95\% confidence interval [CI] 0.67-1.20; VKA: OR 1.04, CI 0.75-1.46).

Binary logistic regression analysis revealed no influence of OAC status on good outcome at 3 months (NOAC: OR 1.25, CI 0.99-1.59; VKA: OR 1.18, CI 0.89-1.56) and mortality at 3 months (NOAC: OR 1.03, CI 0.81-1.30; VKA: OR 1.04, CI 0.78-1.1.37).
\end{abstract}

Conclusions ET can be performed safely and successfully in LVO stroke patients treated with OAC.

Clinical trial registration-URL http://www.clinicaltrials.gov. Unique identifier: NCT03356392.

Keywords Endovascular treatment $\cdot$ Oral anticoagulation $\cdot$ Large vessel occlusion $\cdot$ Ischemic stroke

Supplementary Information The online version contains supplementary material available at https://doi.org/10.1007/s0041 5-020-10369-6.

Lars Kellert

Lars.Kellert@med.uni-muenchen.de

1 Department of Neurology, Ludwig-Maximilians University, Marchioninistraße 15, 81377 Munich, Germany

2 German Center for Vertigo and Balance Disorders, Ludwig-Maximilians University, Munich, Germany

3 Department of Neurology and Stroke, Eberhard-Karls University Tübingen, Universitätsklinikum Tübingen (UKT), Tübingen, Germany

4 Helios Dr. Horst Schmidt Kliniken Wiesbaden, Wiesbaden, Germany
5 Institute for Stroke and Dementia Research, University Hospital, Ludwig-Maximilians University, Munich, Germany

6 Institute of Neuroradiology, Ludwig-Maximilians University, Munich, Germany

7 Department of Neuroradiology, University of Bonn, Bonn, Germany

8 Munich Cluster for Systems Neurology (SyNergy), Munich, Germany 


\section{Introduction}

Stroke treatment for large vessel occlusion (LVO) strokes has been revolutionized in 2015 by the publication of the socalled HERMES trials (Highly Effective Reperfusion Evaluated in Multiple Endovascular Stroke Trials) [3, 4, 6, 8, 18]. Since then, endovascular treatment (ET) is the standard of care in LVO ischemic strokes apart from intravenous thrombolysis (IVT). Nevertheless, it remains unclear whether ET is safe and efficacious in certain patient subgroups. In particular, ET in OAC stroke patients has not been evaluated formally in the HERMES trials. OAC - variably definedwas even an exclusion criterion in some of them. [3, 4, 8, 18] Since then, several mostly small retrospective and four prospective observational studies investigated ET in anticoagulated patients $[2,5,9-17,19,21,22]$. Because of the overwhelming success of ET, large randomized-controlled trials on this topic are not to be expected in the future due to ethical concerns. Therefore, we evaluated the safety and efficacy of ET for LVO stroke in a large cohort of OAC patients compared to non-OAC patients within the prospectively collected data of the German Stroke Registry-Endovascular Treatment (GSR-ET).

\section{Materials and methods}

\section{Study cohort}

The study cohort consisted of patients included to the GSRET, an academic, prospective, multicenter registry study for the systematic evaluation of the outcome, safety, and process parameters of ET in standard of care in Germany. It has been described in depth recently [1,20]. In brief, all consecutive adult patients with LVO stroke with an intention to be treated with ET at 25 German study centers were included to the GSR-ET. For this current evaluation, all GSR-ET patients were analyzed who were either orally anticoagulated or not anticoagulated at the time of stroke based on the local neurologist's evaluation of the patient's medication history and laboratory results if performed locally. Laboratory investigations such as INR or anti factor Xa activity, etc. were not systematically performed and documented in the registry to confirm the medication history. Patients without information on anticoagulation therapy were excluded from the analysis.

\section{Data collection}

Source data were collected at 25 stroke centers in Germany between June 2015 and December 2019, and were assessed and rated by the local neurointerventionalists and neurologists.
Codified data were stored in a web-based electronic database hosted at the University Medical Center Hamburg-Eppendorf.

\section{Efficacy and safety outcomes}

The primary efficacy outcomes were the successful recanalization defined as modified thrombolysis in cerebral infarction (mTICI) score $2 \mathrm{~b}-3$ analyzed by the local neurointerventionalist and the modified Rankin scale (mRS) after 3 months analyzed by the local neurologist either during an outpatient visit or by phone call if the patient could not come to the outpatient clinic. Good outcome at 3 months was defined according to mRS $0-2$ or back to baseline to account for possible pre-stroke disability. The primary safety outcomes were presence of intracranial hemorrhage (ICH) on routine follow-up imaging at $24 \mathrm{~h}$ according to the ECASS II (European Cooperative Acute Stroke Study [part II]) definition [7], irrespective of the presence of new clinical symptoms and without registry documentation of the specific ICH subtype. A secondary analysis included the prediction of good outcome on the mRS at 3 months, death at 3 months and ICH on follow-up imaging at $24 \mathrm{~h}$ by the anticoagulation status adjusted for age, sex, comorbidities, concomitant antiplatelet therapy, stroke severity, and concomitant IVT therapy.

\section{Statistical analysis}

Data are presented as mean \pm standard deviation (SD) or counts and percentages as applicable. Data were analyzed by Kruskal-Wallis test, chi-squared test, or Fisher's exact test as applicable. A Bonferroni correction for multiple testing was used. Differences were accepted as statistically significant for the following $p$ values: $p<0.05, p<0.01$ and $p<0.005$. For secondary analysis, a binary logistic regression analysis adjusting for potential confounder variables was performed with $95 \%$ confidence intervals (CI). Potential confounder variables were determined from meaningful baseline between-group differences of univariate analysis and chosen based on clinical experience (IVT, smoking, atrial fibrillation, diabetes mellitus, arterial hypertension, antiplatelet therapy, sex, age, NIHSS on admission, and pmRS). Additionally, for mRS at d90, an ordinal regression shift analysis was performed. All tests were performed with IBM ${ }^{\circledR}$ SPSS ${ }^{\circledR}$ Statistics Version 26.

\section{Results}

\section{Baseline patient characteristics}

In total, 6636 patients were analyzed of whom 6173 patients fulfilled the inclusion criteria. 1306 (21.2\%) patients were 
treated with OAC: $479(7.8 \%)$ patients had OAC with vitamin K antagonists (VKA) and 827 (13.4\%) patients with non-vitamin $\mathrm{K}$ antagonist oral anticoagulants (NOAC). The control group consisted of 4867 (78.8\%) non-OAC patients. OAC patients were older (VKA $77.7 \pm 10.9$ years, NOAC $77.7 \pm 10.9$ years vs no OAC $72.0 \pm 13.5$ years, $p<0.005$ ) and more NOAC patients were female $(52.6 \%$ and $57.8 \%$ vs $49.5 \%, p=0.11$ and $<0.005)$. Concomitant antiplatelet therapy was less frequent among OAC patients $(5.6 \%$ and $9.4 \%$ vs $37.4 \%, p<0.005)$. As expected, OAC patients had more often atrial fibrillation $(86.9 \%$ and $87.5 \%$ vs $29.9 \%$, $p<0.005)$ but also arterial hypertension $(88.4 \%$ and $86.4 \%$ vs $75.3 \%, p<0.005)$. Also, among OAC patients, diabetes mellitus ( $25.2 \%$ and $28.4 \%$ vs $20.7 \%, p=0.05$ and $<0.005)$ and hyperlipidemia ( $48.4 \%$ and $45.5 \%$ vs $37.9 \%, p<0.005)$ were more frequent, while smoking was less prevalent (17.5\% and $19.4 \%$ vs $27.3 \%, p<0.005)$. Premorbid functional status analyzed by the premorbid mRS was worse in the $\mathrm{OAC}$ patients (median 0 and 0 vs 0 , interquartile range 2 and 2 vs $1, p<0.005$ ) (see Table 1 ).

\section{Stroke, imaging, and treatment characteristics}

Clinical stroke severity analyzed by the National Institute of Health Stroke Scale (NIHSS) showed more severe strokes in OAC patients ( 15 and 15 vs $14, p=0.05$ and $<0.005$ ). The Alberta Stroke Program Early CT Score (ASPECTS) was equally distributed among the three groups ( 9 and 9 vs 9 , $p=0.79$ and 1). Occlusion site of the LVO was similar in all three groups except for extracranial Carotid artery occlusion which was less frequent among NOAC patients $(2.6 \% \mathrm{vs}$ $6.9 \%$ in non-OAC patients, $p<0.005$ ). Also, multiple LVO and occlusion sides were similarly distributed among orally anticoagulated patients and the control group. As expected, IVT was less frequently performed in OAC patients $(26.7 \%$ and $11.0 \%$ vs $59.4 \%, p<0.005)$. Whether IVT in these OAC patients was performed because of subtherapeutic anticoagulation or because these patients were misclassified as nonOAC patients at the time of IVT initiation remains speculative as the GSR-ET did not collect data on this question. If performed on site, IVT was started less fast in OAC than in non-OAC patients (door-to-needle time in minutes $38 \pm 33$ and $46 \pm 26$ vs $33 \pm 49, p<0.005$ ), while in drip-and-ship patients, door-to-needle time was not different $(-93 \pm 118$ and $-72 \pm 60$ vs $-87 \pm 75, p=0.28$ and 0.72 ). ET was initiated (door-to-groin puncture time in minutes $89 \pm 133$ and $97 \pm 156$ vs $101 \pm 151, p=0.21$ and 0.13 ) and terminated (door-to-flow restoration time in minutes $137 \pm 148$ and $137 \pm 149$ vs $139 \pm 134, p=1$ and 0.19 ) similarly fast in OAC compared to non-OAC patients. With regards to stroke etiology, cardioembolic stroke was more frequent among OAC patients both VKA and NOAC patients $(88.9 \%$ and $83.8 \%$ vs $40.7 \%, p<0.005)$. Large artery atherosclerosis $(4.4 \%$ and $4.7 \%$ vs $30.1 \%, p<0.005)$ and undetermined cause $(3.3 \%$ and $6.2 \%$ vs $23.3 \%, p<0.005)$ were less frequent among OAC patients. Also, other determined causes were less frequent among VKA patients (3.3\% vs $5.9 \%, p=0.04)$, while they were similarly frequent among NOAC patients $(5.3 \%$ vs $5.9 \%, p=1$ ) (see Table 2).

\section{Efficacy and safety of ET}

Successful reperfusion (mTICI 2b-3) after ET was achieved with equal frequency among orally anticoagulated patients $(85.6 \%$ and $85.3 \%$ vs $84.3 \%, p=0.93$ and 1) (see Table 3). While on day 90 , good outcome was less frequent in OAC patients in univariate analysis $(31.3 \%$, $31.1 \%$ vs $41.4 \%, p<0.005$ ) (see Table 3 ) binary logistic regression analysis with adjustment for pmRS, NIHSS, age, sex, antiplatelet medication, arterial hypertension,

Table 1 Baseline patient characteristics

\begin{tabular}{lllllll}
\hline Parameter & No OAC & VKA & $p$ value & NOAC & $p$ value & Included patients, $n(\%)$ \\
\hline$n(\%)$ & $4867(78.8)$ & $479(7.8)$ & n. a & $827(13.4)$ & n. a & $6173(100)$ \\
Age, mean \pm SD & $72.0 \pm 13.5$ & $77.7 \pm 10.9$ & $<0.005$ & $77.7 \pm 10.9$ & $<0.005$ & $6169(99.9)$ \\
Female, $n(\%)$ & $2409(49.5)$ & $252(52.6)$ & 0.11 & $469(57.8)$ & $<0.005$ & $6170(100)$ \\
Antiplatelet therapy, $n(\%)$ & $1819(37.4)$ & $27(5.6)$ & $<0.005$ & $78(9.4)$ & $<0.005$ & $6173(100)$ \\
Arterial hypertension, $n(\%)$ & $3632(75.3)$ & $419(88.4)$ & $<0.005$ & $703(86.4)$ & $<0.005$ & $6112(99.0)$ \\
Diabetes mellitus, $n(\%)$ & $998(20.7)$ & $119(25.2)$ & 0.05 & $231(28.4)$ & $<0.005$ & $6107(98.9)$ \\
Hyperlipidemia, $n(\%)$ & $1823(37.9)$ & $228(48.4)$ & $<0.005$ & $368(45.5)$ & $<0.005$ & $6093(98.7)$ \\
Atrial fibrillation, $n(\%)$ & $1438(29.9)$ & $413(86.9)$ & $<0.005$ & $715(87.5)$ & $<0.005$ & $6107(98.9)$ \\
History of smoking, $n(\%)$ & $1208(27.3)$ & $72(17.5)$ & $<0.005$ & $144(19.4)$ & $<0.005$ & $5568(90.2)$ \\
pmRS, median (min, max; inter- & $0(0,5 ; 1)$ & $0(0,5 ; 2)$ & $<0.005$ & $0(0,5 ; 2)$ & $<0.005$ & $6005(97.3)$ \\
$\quad$ quartile range) & & & & & & \\
\hline
\end{tabular}

$O A C$ oral anticoagulation, $V K A$ vitamin $\mathrm{K}$ antagonist, $N O A C$ non-vitamin $\mathrm{K}$ antagonist oral anticoagulant, pmRS premorbid modified Rankin scale 
Table 2 Clinical stroke, imaging, and treatment characteristics

\begin{tabular}{|c|c|c|c|c|c|c|}
\hline Parameter & No OAC & VKA & $p$ value & NOAC & $p$ value & Included patients, $n(\%)$ \\
\hline NIHSS, median (min, max) & $14(0,42)$ & $15(0,42)$ & 0.05 & $15(0,42)$ & $<0.005$ & $6078(98.5)$ \\
\hline ASPECTS, median (min, max) & $9(1,10)$ & $9(1,10)$ & 0.79 & $9(1,10)$ & 1 & $4830(78.2)$ \\
\hline \multicolumn{7}{|l|}{ Occlusion site, $n(\%)$} \\
\hline Carotid artery extracranial & $333(6.9)$ & $22(4.6)$ & 0.11 & $21(2.6)$ & $<0.005$ & \multirow[t]{10}{*}{$6094(98.7)$} \\
\hline Carotid artery intracranial without Carotid-T & $261(5.4)$ & $26(5.5)$ & 1 & $30(3.7)$ & 0.08 & \\
\hline Carotid artery intracranial including Carotid-T & $746(15.5)$ & $91(19.1)$ & 0.08 & $135(16.5)$ & 1 & \\
\hline M1 proximal & $1629(33.9)$ & $142(29.8)$ & 0.15 & $280(34.3)$ & 1 & \\
\hline M1 distal & $977(20.3)$ & $93(19.5)$ & 1 & $161(19.7)$ & 1 & \\
\hline M2 & $982(20.5)$ & $100(21.0)$ & 1 & $172(21.1)$ & 1 & \\
\hline ACA & $104(2.2)$ & $18(3.8)$ & 0.07 & $22(2.7)$ & 0.74 & \\
\hline PCA & $122(2.5)$ & $14(2.9)$ & 1 & $26(3.2)$ & 0.69 & \\
\hline BA & $485(10.1)$ & $35(7.4)$ & 0.13 & $71(8.7)$ & 0.46 & \\
\hline VA & $96(2.0)$ & $8(1.0)$ & 0.10 & $5(1.1)$ & 0.32 & \\
\hline \multicolumn{7}{|l|}{ Occlusion side } \\
\hline Right, $n(\%)$ & $2114(43.4)$ & $200(41.8)$ & 1 & $355(42.9)$ & 1 & \multirow[t]{4}{*}{$6173(100)$} \\
\hline Left, $n(\%)$ & $2333(47.9)$ & $255(53.2)$ & 0.06 & $418(50.5)$ & 0.35 & \\
\hline n. a., e.g., BA, $n(\%)$ & $492(10.1)$ & $34(7.1)$ & 0.07 & $72(8.7)$ & 0.46 & \\
\hline Multiple, $n(\%)$ & $101(2.1)$ & $10(2.1)$ & 1 & $21(2.5)$ & 0.87 & \\
\hline IVT yes, $n(\%)$ & $2892(59.4)$ & $128(26.7)$ & $<0.005$ & $91(11.0)$ & $<0.005$ & $6173(100)$ \\
\hline IVT yes and on site, $n(\%)$ & $1674(34.4)$ & $55(6.7)$ & $<0.005$ & $72(15.0)$ & $<0.005$ & $6173(100)$ \\
\hline Door-to-needle time IVT on site, minutes, mean \pm SD & $33 \pm 49$ & $38 \pm 33$ & $<0.005$ & $46 \pm 26$ & $<0.005$ & $1686(93.6)$ \\
\hline $\begin{array}{l}\text { Door-to-needle time IVT drip-and-ship, minutes, } \\
\text { mean } \pm \mathrm{SD}\end{array}$ & $-87 \pm 75$ & $-93 \pm 118$ & 0.28 & $-72 \pm 60$ & 0.72 & $1310(88.6)$ \\
\hline Door-to-groin puncture time, mean $\pm \mathrm{SD}$ & $101 \pm 151$ & $89 \pm 133$ & 0.21 & $97 \pm 156$ & 0.13 & $5827(94.4)$ \\
\hline Door-to-flow restoration time, mean $\pm \mathrm{SD}$ & $139 \pm 134$ & $137 \pm 148$ & 1 & $137 \pm 149$ & 0.19 & $5091(82.4)$ \\
\hline \multicolumn{7}{|l|}{ Stroke etiology, $n(\%)$} \\
\hline Cardioembolic & $1982(40.7)$ & $426(88.9)$ & $<0.005$ & $693(83.8)$ & $<0.005$ & \multirow[t]{4}{*}{$6173(100)$} \\
\hline Large artery atherosclerosis & $1466(30.1)$ & $21(4.4)$ & $<0.005$ & $39(4.7)$ & $<0.005$ & \\
\hline Other determined cause & $285(5.9)$ & $16(3.3)$ & 0.04 & $44(5.3)$ & 1 & \\
\hline Undetermined cause & $1134(23.3)$ & $16(3.3)$ & $<0.005$ & $51(6.2)$ & $<0.005$ & \\
\hline
\end{tabular}

$O A C$ oral anticoagulation, $V K A$ vitamin $\mathrm{K}$ antagonist, NOAC non-vitamin $\mathrm{K}$ antagonist oral anticoagulant, NIHSS National Institute of Health Stroke Scale, ASPECTS Alberta Stroke Program Early CT Score, ACA anterior cerebral artery, $P C A$ posterior cerebral artery, $B A$ basilar artery, $V A$ vertebral artery, $I V T$ intravenous thrombolysis, $S D$ standard deviation

Table 3 Safety and efficacy outcomes in univariate analysis

\begin{tabular}{lllllll}
\hline Parameter & No OAC & VKA & $p$ value & NOAC & $p$ value & Included patients, $n(\%)$ \\
\hline Reperfusion rate (mTICI 2b-3), $n(\%)$ & $4032(84.3)$ & $404(85.6)$ & 0.93 & $701(85.3)$ & 1 & $6077(98.4)$ \\
ICH 24 h, $n(\%)$ & $712(14.6)$ & $60(12.5)$ & 0.44 & $97(11.7)$ & 0.06 & $6173(100)$ \\
mRS 0-2 on d90, $n(\%)$ & $1672(39.5)$ & $116(27.8)$ & $<0.005$ & $197(27.9)$ & $<0.005$ & $5353(86.7)$ \\
$\begin{array}{l}\text { Good outcome (mRS 0-2 or back to } \\
\quad \text { baseline) on d90, } n(\%)\end{array}$ & $1744(41.4)$ & $130(31.3)$ & $<0.005$ & $218(31.1)$ & $<0.005$ & $5332(86.4 \%)$ \\
\hline
\end{tabular}

$O A C$ oral anticoagulation, VKA vitamin $\mathrm{K}$ antagonist, NOAC non-vitamin $\mathrm{K}$ antagonist oral anticoagulation anticoagulant, $m T I C I$ modified thrombolysis in cerebral infarction, $I C H$ intracranial hemorrhage, $m R S$ modified Rankin scale

diabetes mellitus, atrial fibrillation, smoking, and IVT performed revealed no statistically significant influence of oral anticoagulation status on good outcome at 3 months (NOAC: odd's ratio [OR] 1.25, confidence interval [CI]
0.99-1.586; VKA: OR 1.18, CI 0.89-1.56) (see Fig. 1 and electronic supplemental Table 1). This finding was confirmed with an ordinal regression shift analysis of the $\mathrm{mRS}$ at $\mathrm{d} 90$ which did not reveal a statistically significant 
influence of OAC status on the mRS shift (NOAC: OR 0.90, CI 0.75-1.09; VKA: OR 0.93, CI 0.75-1.15) (see electronic supplemental Table 2). The same was true for mortality at 3 months (NOAC: OR 1.03, CI 0.81-1.30; VKA: OR 1.04, CI 0.78-1.37) (see Fig. 2 and electronic supplemental Table 3). With regards to safety, in the majority of the patients, ICH at $24 \mathrm{~h}$ was determined on CT scans $(n=5079,82 \%)$, while MRI only was used in a minority of 618 patients (10\%). A small subgroup of 229 patients $(3.7 \%)$ was investigated with CT and MRI scans. Neither univariate analysis nor binary logistic regression analysis revealed a statistically significant influence of the oral anticoagulation status on ICH on follow-up imaging at 24 h (univariate: $p=0.44$ and 0.06 ; binary logistic regression: NOAC: OR 0.90, CI 0.67-1.20; VKA: OR 1.04, CI 0.75-1.46) (see Table 3, Fig. 3 and electronic supplemental table 4). Interestingly, within the VKA and the NOAC group IVT did not increase the risk for ICH at $24 \mathrm{~h}$ in univariate analysis (VKA: ICH at $24 \mathrm{~h}$ and IVT vs no IVT: $12.5 \%$ vs $12.5 \%, p=1.0$; NOAC: ICH at $24 \mathrm{~h}$ and IVT vs no IVT: $11.0 \%$ vs $11.8 \%, p=1.0$ ).
Fig. 1 Binary logistic regression analysis for good outcome (mRS 0-2 or back to baseline) at $\mathrm{d} 90 . m R S$ modified Rankin scale, $I V T$ intravenous Institute of Health Stroke Scale, pmRS premorbid modified Rankin scale, $V K A$ vitamin $\mathrm{K}$ antagonist, NOAC non-vitamin $\mathrm{K}$ oral anticoagulation anticoagulant sion analysis for mortality at d90. IVT intravenous thrombolysis, NIHSS National Institute of Health Stroke Scale, $p m R S$ premorbid modified Rankin scale, $V K A$ vitamin $\mathrm{K}$ antagonist, NOAC non-vitamin $\mathrm{K}$ oral anticoagulant thrombolysis, NIHSS National

Fig. 2 Binary logistic regres-

\author{
Parameter: \\ IVT \\ Smoking \\ Atrial fibrillation \\ Diabetes mellitus \\ Arterial hypertension \\ Antiplatelet therapy \\ Sex \\ Age \\ NIHSS \\ pmRS \\ VKA \\ NOAC
}
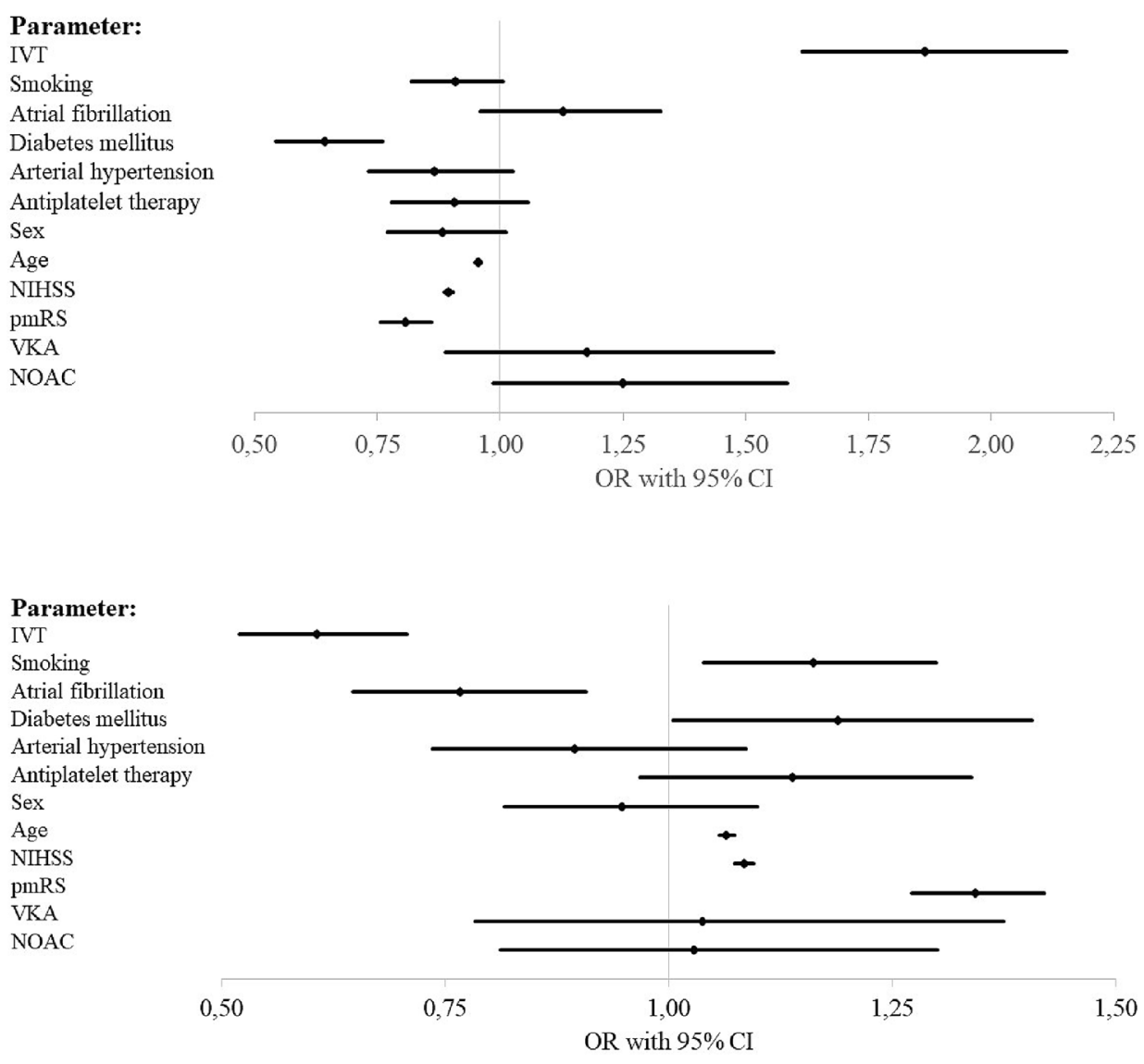

Fig. 3 Binary logistic regression analysis for ICH at $24 \mathrm{~h}$. ICH intracranial hemorrhage, IVT intravenous thrombolysis, NIHSS National Institute of Health Stroke Scale, pmRS premorbid modified Rankin scale, VKA vitamin $\mathrm{K}$ antagonist, NOAC non-vitamin $\mathrm{K}$ oral anticoagulant

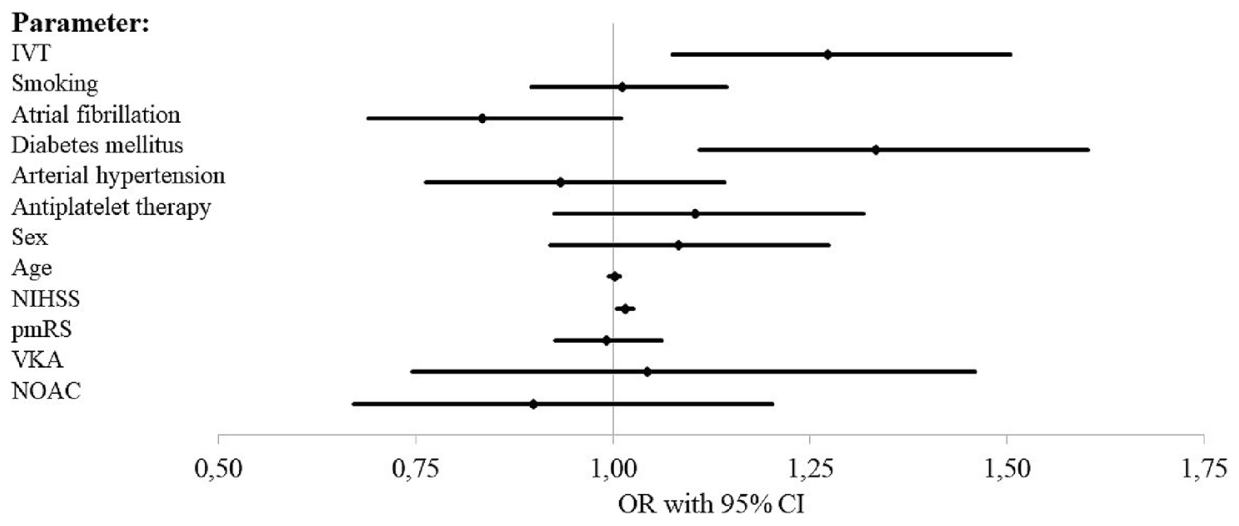




\section{Discussion}

The key findings of our retrospective analysis of a large German prospectively collected observational cohort of LVO stroke patients who received ET in view of their OAC status are as follows: ET in LVO OAC patients is effective and safe with regards to reperfusion rate and postinterventional ICH. Moreover, OAC status did not have a negative influence on the long-term functional outcome after ET. Although LVO OAC patients performed worse on the mRS at 3 months, their OAC status did not affect the rate of good functional outcome and mortality at 3 months after adjustment for possible confounding variables. The poorer performance of OAC patients on the mRS at 3 months might at least be in part explained by their worse premorbid functional status (higher premorbid mRS), their older age, and the more sever strokes in NOAC patients (higher NIHSS). All three of these variables had a negative impact on the rate of good outcome at 3 months in the multivariate analysis. In addition, comorbidities were more frequent among OAC patients. In contrast, differences in the pre-interventional imaging on admission as a possible confounder for the clinical efficacy of ET in OAC patients can be excluded as ASPECTS on admission and type and side of LVO were in general comparable among OAC and non-OAC LVO stroke patients. Also, ET was initiated and finished equally fast in OAC and non-OAC patients. This excludes a prolongation of the procedural times in non-OAC patients due to higher rates of IVT or in OAC patients due to a more difficult decision process before performing ET and/or IVT which could have had an impact on the technical and clinical outcomes.

Our analysis comprises the highest number of patients with 6173 in total and 1306 OAC patients compared to the recently published studies with a total number of patients ranging from 28 to 1913 and a number of OAC patients ranging from 26 to 320 [2, 5, 9-17, 19, 21, 22]. Most studies published retrospectively collected data, but four studies were prospective cohort studies [2, 5, 9-17, $19,21,22]$. With regards to technical efficacy of ET, if reported, all studies showed similar reperfusion rates in OAC and non-OAC patients as in our GSR-ET cohort [2, $5,9,11,16,19,21,22]$. Nevertheless, the reperfusion rates were distributed heterogeneously among the different studies ranging from 64 to $93 \%[2,5,9,11,16,19,21$, 22]. Additionally, one study compared ET in VKA and NOAC patients and reported on better reperfusion rates among NOAC patients [12] which was not reflected by our data showing similar reperfusion rates among OAC and non-OAC patients. Clinical efficacy of ET in OAC patients compared to non-OAC patients analyzed by the mRS at 3 months was reported to be good in most of the recently published studies $[2,9,11,16,17,21,22]$. Nevertheless, one Czech study found that an mRS 0-2 on day 90 seemed to be less frequent among patients on anticoagulation therapy, but those patients were older and had more comorbidities [5]. Similarly, another study reported worse outcome on $\mathrm{d} 90$ among patients on VKA, but again this turned out to be mainly attributable to higher age [19]. Supporting these observations, in our own analysis after adjustment for possible confounding factors including age and comorbidities, neither NOAC nor VKA treatment did have a negative impact on the long-term clinical efficacy of ET. With regards to mortality, one French study reported a higher mortality rate at three months in anticoagulated patients anticoagulated with VKA, NOAC, or heparin [11]. Another recent multicenter observational cohort study published together with a study-level meta-analysis found an increased mortality at 90 days specifically for VKA patients but not for NOAC patients receiving MT [13]. In general, other published studies [2, 5, 9, 16, 21, 22] and our own data did not support this observation: in our patients, neither VKA nor NOAC intake on admission increased mortality on d90 after MT. These findings on the mortality rate are in accordance with the published ICH rates as a safety parameter that did not seem to be higher among the OAC patients as in our cohort although reported differentially detailed $[2,5,9-11,14,16,17,19,21,22]$. Interestingly, the multicenter observational cohort study that had already reported on increased mortality among VKA patients also found increased rates of symptomatic intracranial hemorrhage among these patients which might at least explain the higher mortality rates [13]. Our own study did not see higher ICH rates among VKA and NOAC patients, although our data are not directly comparable as we evaluated any ICH on $24 \mathrm{~h}$ imaging that means not only symptomatic but also asymptomatic.

In summary, our analysis of the GSR-ET as the largest available cohort supports the general impression from the literature that ET is safe and efficacious in OAC patients. In particular, long-term functional outcome and mortality were not influenced by OAC status. Additionally, intracranial hemorrhage rates were not increased.

Nevertheless, our analysis has several limitations: first, our data are of observational character. Therefore, generalizability has to be assumed with caution only. Yet, given the overwhelming success of ET in LVO strokes, it will be difficult to generate randomized-controlled data on this topic in the future due to ethical concerns which underscores the importance of large retrospective analyses such as ours. Second, the OAC status of our patients was not verified by laboratory results such as INR, specific drug activity measurement, etc. as they were not broadly documented in our study database. This might have led to misclassification of some patients. Third, data on some parameters were missing which might have influenced 
our interpretation of the results. Fourth, ICH on postinterventional imaging was not further characterized in the registry which limits the interpretation of the safety of ET in OAC patients. Additionally, in a majority of the patients, hemorrhagic transformation at $24 \mathrm{~h}$ was determined by CT scans without further distinguishing between dual-energy and ordinary CT scan within the registry. CT scans at $24 \mathrm{~h}$ might not be able to differentiate fairly enough between $\mathrm{ICH}$ and postinterventional blood-brain barrier disruption (BBRD) compared to imaging at $72 \mathrm{~h}$ or alternative imaging modalities such as MRI.

\section{Conclusion}

ET in OAC patients with acute LVO ischemic strokes should be strongly considered as it is a safe and efficacious treatment.

Author contributions The study was designed and conceptualized by CK and LK. Data collection was performed by CK, KF, ST, and MH. $\mathrm{CK}$ analyzed the data and wrote the first draft of the manuscript. All authors commented on previous versions of the manuscript. All authors read and approved the final manuscript.

Funding Open Access funding enabled and organized by Projekt DEAL.. The authors received no financial support for the research, authorship, and publication of this article.

Data availability The data that support the findings of this study are available from the corresponding author upon reasonable request.

\section{Compliance with ethical standards}

Conflicts of interest $\mathrm{CK}, \mathrm{KF}, \mathrm{ST}, \mathrm{MH}, \mathrm{FD}$, and MD have nothing to disclose. FAW reports personal fees from Bayer, Pfizer-BMS, Portola, and Boehringer Ingelheim outside of this study. TL consults for Stryker Neurovascular GmbH and has received speaker honoraria by Pfizer, Covidien, Phenox, and Microvention outside this study. LK has received funding for travel or speaker honoraria from Bayer Vital, Boehringer Ingelheim, Bristol-Meyer-Squibb, Daiichi Sankyo, and Pfizer outside of this study.

Ethical approval The study was centrally approved by the Ethics Committee of the Ludwig Maximilians University LMU, Munich (68915 ), as the leading ethics committee. Further approval was obtained from local ethics committees or institutional review boards according to local regulations. The study was conducted in accordance with the 1964 Declaration of Helsinki and its later amendments.

Informed consent An informed consent was not mandatory in accordance with the institutional review board approval, because no studyspecific procedures were performed and data sampling from patients undergoing ET is already mandated by national law for quality control reasons.

Open Access This article is licensed under a Creative Commons Attribution 4.0 International License, which permits use, sharing, adaptation, distribution and reproduction in any medium or format, as long as you give appropriate credit to the original author(s) and the source, provide a link to the Creative Commons licence, and indicate if changes were made. The images or other third party material in this article are included in the article's Creative Commons licence, unless indicated otherwise in a credit line to the material. If material is not included in the article's Creative Commons licence and your intended use is not permitted by statutory regulation or exceeds the permitted use, you will need to obtain permission directly from the copyright holder. To view a copy of this licence, visit http://creativecommons.org/licenses/by/4.0/.

\section{References}

1. Alegiani AC, Dorn F, Herzberg M, Wollenweber FA, Kellert L, Siebert E, Nolte $\mathrm{CH}$, von Rennenberg R, Hattingen E, Petzold GC, Bode FJ, Pfeilschifter W, Schafer JH, Wagner M, Rother J, Eckert B, Kraft P, Pham M, Boeckh-Behrens T, Wunderlich S, Bernkopf K, Reich A, Wiesmann M, Mpotsaris A, Psychogios M, Liman J, Maier I, Berrouschot J, Bormann A, Limmroth V, Spreer J, Petersen M, Krause L, Lowens S, Kraemer C, Zweynert S, Lange KS, Thonke S, Kastrup A, Papanagiotou P, Alber B, Braun M, Fiehler J, Gerloff C, Dichgans M, Thomalla G (2019) Systematic evaluation of stroke thrombectomy in clinical practice: The German Stroke Registry Endovascular Treatment. Int J Stroke 14:372-380

2. Benavente L, Larrosa D, Garcia-Cabo C, Perez AI, Rico M, Vega P, Murias E, Calleja S (2016) Safety and efficacy of mechanical thrombectomy in acute ischemic stroke of anticoagulated patients-a prospective observational study. J Stroke Cerebrovasc Dis 25:2093-2098

3. Berkhemer OA, Fransen PS, Beumer D, van den Berg LA, Lingsma HF, Yoo AJ, Schonewille WJ, Vos JA, Nederkoorn PJ, Wermer MJ, van Walderveen MA, Staals J, Hofmeijer J, van Oostayen JA, Lycklama a Nijeholt GJ, Boiten J, Brouwer PA, Emmer BJ, de Bruijn SF, van Dijk LC, Kappelle LJ, Lo RH, van Dijk EJ, de Vries J, de Kort PL, van Rooij WJ, van den Berg JS, van Hasselt BA, Aerden LA, Dallinga RJ, Visser MC, Bot JC, Vroomen PC, Eshghi O, Schreuder TH, Heijboer RJ, Keizer K, Tielbeek AV, den Hertog HM, Gerrits DG, van den Berg-Vos RM, Karas GB, Steyerberg EW, Flach HZ, Marquering HA, Sprengers ME, Jenniskens SF, Beenen LF, van den Berg R, Koudstaal PJ, van Zwam WH, Roos YB, van der Lugt A, van Oostenbrugge RJ, Majoie CB, Dippel DW, Investigators MC (2015) A randomized trial of intraarterial treatment for acute ischemic stroke. N Engl J Med 372:11-20

4. Campbell BC, Mitchell PJ, Kleinig TJ, Dewey HM, Churilov L, Yassi N, Yan B, Dowling RJ, Parsons MW, Oxley TJ, Wu TY, Brooks M, Simpson MA, Miteff F, Levi CR, Krause M, Harrington TJ, Faulder KC, Steinfort BS, Priglinger M, Ang T, Scroop R, Barber PA, McGuinness B, Wijeratne T, Phan TG, Chong W, Chandra RV, Bladin CF, Badve M, Rice H, de Villiers L, Ma H, Desmond PM, Donnan GA, Davis SM, Investigators E-I (2015) Endovascular therapy for ischemic stroke with perfusion-imaging selection. N Engl J Med 372:1009-1018

5. Cernik D, Sanak D, Divisova P, Kocher M, Cihlar F, Zapletalova J, Veverka T, Prcuchova A, Ospalik D, Cerna M, Janousova P, Kral M, Dornak T, Prasil V, Franc D, Kanovsky P (2018) Mechanical thrombectomy in patients with acute ischemic stroke on anticoagulation therapy. Cardiovasc Intervent Radiol 41:706-711

6. Goyal M, Demchuk AM, Menon BK, Eesa M, Rempel JL, Thornton J, Roy D, Jovin TG, Willinsky RA, Sapkota BL, Dowlatshahi D, Frei DF, Kamal NR, Montanera WJ, Poppe AY, Ryckborst KJ, Silver FL, Shuaib A, Tampieri D, Williams D, Bang OY, Baxter BW, Burns PA, Choe H, Heo JH, Holmstedt CA, Jankowitz B, Kelly M, Linares G, Mandzia JL, Shankar J, Sohn SI, Swartz RH, Barber PA, Coutts SB, Smith EE, Morrish WF, Weill A, Subramaniam S, Mitha AP, Wong JH, Lowerison MW, Sajobi TT, Hill MD, Investigators ET (2015) Randomized assessment 
of rapid endovascular treatment of ischemic stroke. N Engl J Med 372:1019-1030

7. Hacke W, Kaste M, Fieschi C, von Kummer R, Davalos A, Meier D, Larrue V, Bluhmki E, Davis S, Donnan G, Schneider D, DiezTejedor E, Trouillas P (1998) Randomised double-blind placebocontrolled trial of thrombolytic therapy with intravenous alteplase in acute ischaemic stroke (ECASS II). Second European-Australasian Acute Stroke Study Investigators. Lancet 352:1245-1251

8. Jovin TG, Chamorro A, Cobo E, de Miquel MA, Molina CA, Rovira A, San Roman L, Serena J, Abilleira S, Ribo M, Millan M, Urra X, Cardona P, Lopez-Cancio E, Tomasello A, Castano C, Blasco J, Aja L, Dorado L, Quesada H, Rubiera M, Hernandez-Perez M, Goyal M, Demchuk AM, von Kummer R, Gallofre M, Davalos A, Investigators RT (2015) Thrombectomy within 8 hours after symptom onset in ischemic stroke. N Engl J Med 372:2296-2306

9. Krajickova D, Krajina A, Herzig R, Vitkova E, Haluskova S, Vysata O, Cabelkova P, Valis M (2019) Safety and efficacy of mechanical thrombectomy with stent-retrievers in anticoagulated patients with anterior circulation stroke. Clin Radiol 74:165111-165116

10. Kurowski D, Jonczak K, Shah Q, Yaghi S, Marshall RS, Ahmad H, McKinney J, Torres J, Ishida K, Cucchiara B (2017) Safety of endovascular intervention for stroke on therapeutic anticoagulation: multicenter cohort study and meta-analysis. J Stroke Cerebrovasc Dis 26:1104-1109

11. L'Allinec V, Ernst M, Sevin-Allouet M, Testard N, Delasalle-Guyomarch B, Guillon B, Mazighi M, Desal H, Bourcier R, Investigators NTF (2018) Safety and efficacy of mechanical thrombectomy in acute ischemic stroke of anticoagulated patients. J Neurointerv Surg 10:e29

12. L'Allinec V, Sibon I, Mazighi M, Labreuche J, Kyheng M, Boissier E, Roy M, Gory B, Dargazanli C, Desal H, Lapergue B, Bourcier R, Treatment E, Endovascular Treatment in Ischemic Stroke I (2020) MT in anticoagulated patients: direct oral anticoagulants versus vitamin K antagonists. Neurology 94:e842-e850

13. Meinel TR, Kniepert JU, Seiffge DJ, Gralla J, Jung S, Auer E, Frey S, Goeldlin M, Mordasini P, Mosimann PJ, Nogueira RG, Haussen DC, Rodrigues GM, Uphaus T, L'Allinec V, Krajickova D, Alonso A, Costalat V, Hajdu SD, Olive-Gadea M, Maegerlein C, Pierot L, Schaafsma J, Suzuki K, Arnold M, Heldner MR, Fischer U, Kaesmacher J (2020) Endovascular stroke treatment and risk of intracranial hemorrhage in anticoagulated patients. Stroke 51:892-898

14. Mundiyanapurath S, Tillmann A, Mohlenbruch MA, Bendszus M, Ringleb PA (2017) Endovascular stroke therapy may be safe in patients with elevated international normalized ratio. J Neurointerv Surg 9:1187-1190

15. Purrucker JC, Wolf M, Haas K, Rizos T, Khan S, Dziewas R, Kleinschnitz C, Binder A, Groschel K, Hennerici MG,
Lobotesis K, Poli S, Seidel G, Neumann-Haefelin T, Ringleb PA, Heuschmann PU, Veltkamp R (2016) Safety of endovascular thrombectomy in patients receiving non-vitamin $\mathrm{K}$ antagonist oral anticoagulants. Stroke 47:1127-1130

16. Rebello LC, Haussen DC, Belagaje S, Anderson A, Frankel M, Nogueira RG (2015) Endovascular treatment for acute ischemic stroke in the setting of anticoagulation. Stroke 46:3536-3539

17. Rozeman AD, Wermer MJ, Lycklama a Nijeholt GJ, Dippel DW, Schonewille WJ, Boiten J, Algra A, group MCp-ts (2016) Safety of intra-arterial treatment in acute ischaemic stroke patients on oral anticoagulants. A cohort study and systematic review. Eur J Neurol 23:290-296

18. Saver JL, Goyal M, Bonafe A, Diener HC, Levy EI, Pereira VM, Albers GW, Cognard C, Cohen DJ, Hacke W, Jansen O, Jovin TG, Mattle HP, Nogueira RG, Siddiqui AH, Yavagal DR, Baxter BW, Devlin TG, Lopes DK, Reddy VK, du Mesnil de Rochemont R, Singer OC, Jahan R, Investigators SP (2015) Stent-retriever thrombectomy after intravenous t-PA vs. t-PA alone in stroke. $\mathrm{N}$ Engl J Med 372:2285-2295

19. Uphaus T, Singer OC, Berkefeld J, Nolte CH, Bohner G, Niederkorn K, Deutschmann H, Haring HP, Trenkler J, Neumann-Haefelin T, Hofmann E, Stoll A, Bormann A, Bussmeyer M, Mpotsaris A, Reich A, Wiesmann M, Petzold GC, Urbach H, Jander S, Turowski B, Weimar C, Schlamann M, Liebeskind DS, Groschel S, Boor S, Groschel K (2017) Safety of endovascular treatment in acute stroke patients taking oral anticoagulants. Int J Stroke 12:412-415

20. Wollenweber FA, Tiedt S, Alegiani A, Alber B, Bangard C, Berrouschot J, Bode FJ, Boeckh-Behrens T, Bohner G, Bormann A, Braun M, Dorn F, Eckert B, Flottmann F, Hamann GF, Henn KH, Herzberg M, Kastrup A, Kellert L, Kraemer C, Krause L, Lehm M, Liman J, Lowens S, Mpotsaris A, Papanagiotou P, Petersen M, Petzold GC, Pfeilschifter W, Psychogios MN, Reich A, von Rennenberg R, Rother J, Schafer JH, Siebert E, Siedow A, Solymosi L, Thonke S, Wagner M, Wunderlich S, Zweynert S, Nolte CH, Gerloff C, Thomalla G, Dichgans M, Fiehler J (2019) Functional outcome following stroke thrombectomy in clinical practice. Stroke 50:2500-2506

21. Wong JWP, Churilov L, Dowling R, Mitchell P, Bush S, Kanesan L, Yan B (2018) Safety of endovascular thrombectomy for acute ischaemic stroke in anticoagulated patients ineligible for intravenous thrombolysis. Cerebrovasc Dis 46:193-199

22. Zapata-Wainberg G, Ximenez-Carrillo A, Trillo S, Fuentes B, Cruz-Culebras A, Aguirre C, Alonso de Lecinana M, Vera R, Barcena E, Fernandez-Prieto A, Mendez-Cendon JC, Caniego JL, Diez-Tejedor E, Masjuan J, Vivancos J, Madrid Stroke N (2018) Mechanical thrombectomy in orally anticoagulated patients with acute ischemic stroke. J Neurointerv Surg 10:834-838 